\title{
Fresh Starts
}

KATE MATSUDAIRA

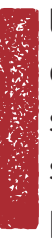

love fresh starts. Growing up, one of my favorite things was starting a new school year. From the fresh school supplies (I am still a sucker for pen and paper) to the promise of a new class of students, teachers, and lessons, I couldn't wait for summer to be over and to go back to school.

The same thing happens with new jobs land to some extent, new teams and new projects]. They reinvigorate you, excite you, and get you going.

The trouble is that starting anew isn't something you get to do all the time. For some people it might happen once a year, once every two years, or once every four years. Furthermore, learning something new isn't always in the best interest of your employer. Of course, great managers want you constantly to be learning and advancing your career, but if you are doing your job well, they also probably like the idea of keeping you in that role where they can rely on you to get the work done. Putting you into a position where you will have to work hard to learn new skills isn't always best for your company-and so it probably doesn't happen often.

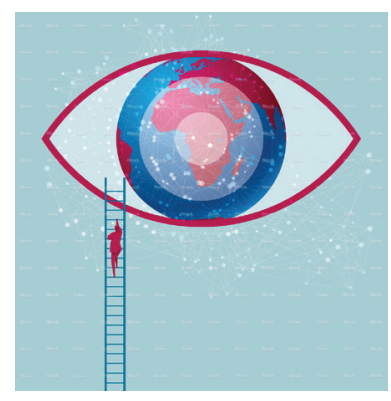

acmqueue |july-august 20161 
Wouldn't it be great if you frequently were in a position where you were pushed to grow outside of your comfort zone? Where you had to start new and fresh?

Well, the good news is that you can. In fact, you can make your current position one that focuses on your growth and extends the boundaries of your knowledgeand that is all up to you.

In technology and computer science, almost more than any other field, a growth mindset is mandatory for success. In this field the tools and best practices are constantly evolving-there is always something new to learn. For many people this high rate of change can be overwhelming, but for the right person this can mean opportunity. When you are willing to dive in and learn new skills, it puts you ahead of the game; and when you are strategic about what skills you learn, it can help you grow your career even faster.

No matter where you are in your career, there is more to learn. All of us can always use an excuse to get more invigorated and excited by our jobs. Here are three steps you can take to develop your current role and make tomorrow [or even the rest of today] a fresh start.

\section{Create a learning plan}

When you have been doing a job for a while, there isn't as much for you to learn in your day-to-day. Sure, there are always opportunities to improve little things, but your rate of knowledge acquisition slows down the longer you have been in a position. This makes it even more important to have a learning plan. You should have a list of things you plan to learn with some concrete tasks associated with 


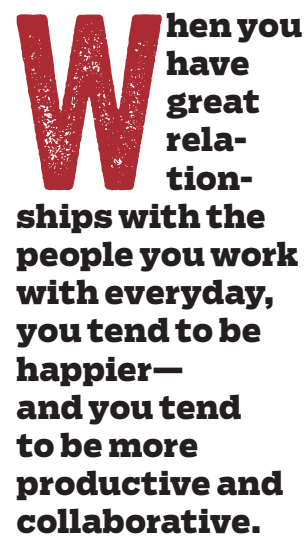

each. If you need some inspiration on what should be on this list, here are some questions to ponder:

$\Rightarrow$ To be promoted to the next level in your job, what do you need to accomplish? Are there any skills you need to acquire or improve?

$\Rightarrow$ If you think 10 years into the future, what do you want to do? Do you know anyone doing that now? What do they know that you don't?

$\Rightarrow$ Look back over your past performance reviews. Are there any areas where you could continue to develop and improve? If you ask others for feedback, what would they say and how can you do better?

\section{Build better relationships}

Most of us spend more time with our coworkers than our families. When you have great relationships with the people you work with every day, you tend to be happierand you tend to be more productive and collaborative. Also, when people like you and want to help you, then you are more likely to get promoted and discover opportunities. Here are two ideas for improving your working relationships:

$\Rightarrow$ Improve your communication skills. When you get better at writing emails, or verbal presentation, you help share information, and this creates better decision-making across your whole team.

$\Rightarrow$ Take someone to lunch. If you work with someone you don't know very well, or haven't had the best working relationship with, make the first move and ask this person to lunch or coffee. This is a great way to get to know people 
and understand their points of view. Working relationships are usually strained because two sides are making incorrect assumptions, and the first step is opening the lines of communication. Be open, practice your listening skills, and offer to foot the bill-for the cost of a lunch you would be amazed at how much that gesture can improve your work life.

\section{Make better use of your down time}

One of my favorite time-management tricks is using spare minutes to maximize your learning. When you can make the most of the small moments and learn things that help advance your career, then you will be one step ahead. This can be as simple as nixing social-media checks and replacing them with 10-15 minutes of reading articles or websites that help increase your knowledge. Here are some other ideas to get more out of those little moments:

$\Rightarrow$ Be on time. When you can start on time and end on time, you make the most of meetings (plus it is a sign of respect when you show up when you say you will], and you will have more freedom to do what you want to do.

$\Rightarrow$ Keep a reading queue. Whether you use bookmarks, notes, or some other tool, keep a list of items you want to read. These can be articles, whitepapers, or books-but when you have a list it is much easier just to go there to fill 15 minutes with useful learning than to spend those 15 minutes surfing the web looking for something interesting.

$\Rightarrow$ Listen to audiobooks or smart podcasts. Whether it is on your commute or when you are working out, if you can't sit and read, try listening to your lessons. There are so 
many great options here, and it is a great way to maximize time and knowledge.

Of course, there are lots of other great ways to make your old career new again, but these little ideas could give you inspiration so that when you come to work tomorrow you can be excited.

If you have any other thoughts or suggestions, feel free to leave them in the comments on the website. And if there is a topic you would like to see covered in this column, let me know.

Kate Matsudaira is an experienced technology leader. She worked in big companies such as Microsoft and Amazon and three successful startups (Decide acquired by eBay, Moz, and Delve Networks acquired by Limelight] before starting her own company, Popforms (https:I/popforms.com/), which was acquired by Safari Books. Having spent her early career as a software engineer, she is deeply technical and has done leading work on distributed systems, cloud computing, and mobile. She has experience managing entire product teams and research scientists, and has built her own profitable business. She is a published author, keynote speaker, and has been honored with awards such as Seattle's Top 40 under 40. She sits on the board of acmqueue and maintains a personal blog at katemats.com.

Copyright $(0) 2016$ held by ownerlauthor. Publication rights licensed to ACM. 